\title{
Identifying single nucleotide polymorphisms (SNPs) and detecting c-reactive protein (CRP) levels associated with posterior circulation ischemia and cerebral infarction
}

\section{Wanhua Chen}

Department of Clinical Laboratory, First Hospital of Quanzhou, Fujian Medical University, Quanzhou, Fujian China

\section{Teng Lin}

Taokang Institute of Neuro Medicine, Xiamen, Fujian China

\section{Lei Xiao}

Taokang Institute of Neuro Medicine, Xiamen, Fujian China

\section{Wenjie Cai}

Department of Radiation Oncology, First Hospital of Quanzhou, Fujian Medical University, Quanzhou, Fujian China

\section{Zhiwei Zeng}

Center for Precision Medicine, School of Medicine and School of Biomedical Sciences, Huaqiao University, Xiamen, Fujian China

\section{Tao Sun}

Center for Precision Medicine, School of Medicine and School of Biomedical Sciences, Huaqiao University, Xiamen, Fujian China

\section{Renliang Chen ( $\square$ melo@taokangneuro.com )}

Taokang Institute of Neuro Medicine, Xiamen, Fujian China https://orcid.org/0000-0002-5850-7862

\section{Research}

Keywords: Cerebrovascular Diseases, Immune System Pathway, Systemic Inflammation, Allele-specific Polymerase Chain Reaction, Simoa Method

Posted Date: March 26th, 2021

DOl: https://doi.org/10.21203/rs.3.rs-358781/v1

License: (c) (i) This work is licensed under a Creative Commons Attribution 4.0 International License. Read Full License 


\section{Abstract}

Background: Posterior circulation ischemia $(\mathrm{PCl})$ and cerebral infarction $(\mathrm{Cl})$ are major cerebrovascular diseases. Screening potential genetic variations such as single nucleotide polymorphisms (SNPs) in genes involved in the immune system pathway is a reliable assessment of potential risk factors for $\mathrm{PCl}$ and $\mathrm{Cl}$. Moreover, C-reactive protein (CRP) is recognized as a sensitive biomarker for systemic inflammation and secondary lesions related to cerebrovascular diseases, which has a significant clinical significance.

Methods: We collected whole blood and plasma samples from 39 healthy controls, $23 \mathrm{PCl}$ and $18 \mathrm{Cl}$ subjects. Allele-specific polymerase chain reaction (AS-PCR) was used to detect mutations in SNPs. The plasma CRP levels were measured using the newly developed single molecule array (Simoa) method.

Results: We detected mutations in three SNPs such as rs3093077, rs3917368 and rs4129267, which are associated with an increased risk of $\mathrm{PCl}$ and $\mathrm{Cl}$. We also captured a significant increase in Simoameasured CRP levels in plasma of patients with $\mathrm{PCl}$ and $\mathrm{Cl}$, compared to healthy controls.

Conclusions: These three identified SNPs can be used as a prediction and evaluation of risk for $\mathrm{PCl}$ and $\mathrm{Cl}$. Our results demonstrate the high sensitivity of Simoa in detecting plasma CRP levels. Our study highlights that AS-PCR and Simoa technology can be used as sensitive clinical diagnostic methods for $\mathrm{PCl}$ and $\mathrm{Cl}$.

\section{Introduction}

Posterior circulation ischemic $(\mathrm{PCl})$ stroke is a clinical syndrome associated with ischemia related to stenosis, in situ thrombosis, or embolic occlusion of the posterior circulation arteries-the vertebral arteries in the neck, the intracranial vertebral, basilar, and posterior cerebral arteries, and their branches (Chen et al. 2018; Murai et al. 2008). Patients with symptomatic vertebral basilar artery stenosis have a 3fold increased risk of stroke after transient ischemic attack (TIA) or mild stroke than patients without stenosis. In addition, cerebral infarction (Cl) is a common cerebrovascular disease that can lead to neurological damages such as exercise weakness, speech dysfunction, vision loss, dizziness, severe headache, and even death. Beside of imaging approaches, we lack of characteristic biomarkers for precise diagnostics for cerebrovascular diseases.

C-reactive protein (CRP) is released mainly by the liver in response to interleukin-6 (IL-6) and IL-1 after inflammatory insults (Pepys et al. 2003). As a biomarker of chronic inflammation, the association of CRP expression level with various diseases has been studied. For example, single nucleotide polymorphism (SNP) studies have shown that increased serum CRP levels are associated with CRP rs3093077 $(\mathrm{p}<0.001)$ in patients with early $(\mathrm{p}=0.016)$ and late $(\mathrm{p}<0.001)$ diabetes (Qi et al. 2009). Whole GenomeWide Association Studies (GWAS) also have identified a variant rs11265259, which is associated with CRP levels in 200,000 individuals of European descent (Raffield et al. 2020). In addition to the SNPs of the CRP gene, some other SNPs of inflammation related genes, such as rs4129267 and rs6734238 of IL- 
$6 R$ and IL-1F10 loci, respectively, also have been found significantly associated with coronary heart disease (Sabater et al. 2013). SNP rs3917368 of IL-1B has been shown to be related to thyroid ophthalmopathy in Taiwanese, and related to hay fever in Japanese (Fuji et al. 2018). These studies indicate an essential association of SNPs with inflammatory immune system diseases. However, whether these SNPs are related to CRP levels and are associated with $\mathrm{PCl}$ and $\mathrm{Cl}$ have not been explored.

Furthermore, because CRP is a sensitive biomarker for systemic inflammation for infection, trauma, surgery, burns, tissue reaction infarction, advanced cancer and chronic inflammation, it has a great potential for predicting secondary lesions associated with cerebrovascular diseas (Gabay et al. 1999). However, it has been a challenge to detect accurate levels of CRP in blood samples.

In this study, to establish disease risk of important SNPs of inflammation related genes in $\mathrm{PCl}$ and $\mathrm{Cl}$, we examined five SNPs by using allele-specific polymerase chain reaction (AS-PCR) (Darawi et al. 2013). ASPCR, also known as amplification of refractory mutation system (ARMS), is a method based on polymerase chain reaction and can be used to detect known SNPs (Kwok et al. 2003). AS-PCR has been widely used in many research fields such as hereditary diseases and pharmacogenetics (Chen et al. 2007; Mirasena et al. 2008).Among the five SNPs, rs3093077 (CRP), rs4129267 (IL-6R) and rs3917368 (IL-1B) displayed a correlation with $\mathrm{PCl}$ and $\mathrm{Cl}$. Moreover, to detect the concentration of CRP in plasma, we applied the single molecule array (Simoa) technique. Compared with healthy subjects, we detected a significantly higher plasma CRP levels in subjects with $\mathrm{PCl}$ and $\mathrm{Cl}$ using Simoa. Moreover, we examined the correlation between SNP mutations and CRP levels. Our results indicate that SNP mutations have a potential influence on CRP levels and are associated with $\mathrm{PCl}$ and $\mathrm{Cl}$. Our study also indicates a useful tool of Simoa to detect CRP levels under the disease condition.

\section{Methods}

Apparatus

The ABI Quant Studio 6 ( $\mathrm{ABI}$ /USA) has 5-colorxcitation light filters and 5-color detection light filters, which can detect up to 5 colors of fluorescence simultaneously, supporting multi-target detection. Consumables such as rapid 96 -well $(0.1 \mathrm{~mL})$ reaction plate and optical cover film, $0.1 \mathrm{~mL}$ eight-connecting tube, $0.1 \mathrm{~mL}$ single tube, and 384-well reaction plate and optical cover film were used.

In addition, the Simoa HD-1 analyzer (Quanterix@, USA) was used for immunoassay. Immune complexes attached to magnetic beads were captured and individually enclosed in microwells on a Simoa disc. The Simoa disc was manufactured by Sony DADC. Each disc contained 24 array chips and could detect 24 samples. Each chip had 216,000 micropores, and each micropore could hold one magnetic bead with or without an immune complex.

Plasma sample collection 
This study was approved by the Institution Ethic Issue Committee of the First Hospital of Quanzhou, Quanzhou, Fujian China (2019-107). Blood samples were collected from healthy, posterior circulation ischemia and cerebral infarction individuals. Plasma was separated through a centrifuge and stored at $-80^{\circ} \mathrm{C}$ until use.

Allele-specific polymerase chain reaction (AS-PCR) assay

DNA was extracted from $200 \mu$ venous blood per subject using a DNA extraction kit (Blood Genomic DNA mini kit, CW0541S) according to the manufacturer's protocol. Primer Premier 5 software was used and specific primers were designed according to the principles of base complementary pairing and mismatch. Primer verification was assisted by Sanger sequencing, and genotype was interpreted according to $\triangle \mathrm{Ct}$ calculation and analysis. PCR amplification was performed in $20 \mu \mathrm{L}$ reactions of $10 \mathrm{pmol} / \mu \mathrm{L}$ of respective primers, $100 \mu \mathrm{M}$ dNTPs, $1 \mathrm{mM} \mathrm{MgCl}_{2}, 1$ X PCR buffer, $0.5 \mathrm{U}$ Taq Polymerase and $50 \mathrm{ng} / \mu \mathrm{L}$ of DNA samples. DNA was denatured at $95^{\circ} \mathrm{C}$ for 30 s, followed by 35 cycles of denaturation at $95^{\circ} \mathrm{C}$ for $5 \mathrm{~s}$, annealing and extension at $60^{\circ} \mathrm{C}$ for $30 \mathrm{~s}$.

Single nucleotide polymorphisms (SNP) analysis and primer design

We identified mutations in both $\mathrm{PCl}$ and $\mathrm{Cl}$ samples by detecting five candidate SNPs using AS-PCR in combination with fluorescence. SNPs such as rs11265259, rs3093077, rs4129267 and rs6734238 are located in the promoter regions of $C R P, I L-1 F 10$ and $I L-6 R$ genes, respectively, and rs3917368 is located in the coding region of $I L-1 B$ gene. According to the sequences of wild-type $(W)$ and mutation $(M)$ of SNPs, specific amplification primers were designed based on the principle of AS-PCR primer design to identify genotypes.

rs 11265259: W-F: 5'-CACGATAAAGCACAAAATGAGAGAT-3', M-F : 5'-CACGATAAAGCACAAAATGAGAGAC-3', R: 5'-TGGCTATCTATGCTATTTGGTGG-3'; rs3093077: W-F: 5'-CCAGCCAAGTAAGACAACCCA-3', M-F: 5'TCCAGGTAAGTACGACATCCCC-3', R: 5'-ACTATCCTCAGGTTTGATGTGCC-3'; rs4129267: W-F: 5'GCTTGGTGTGGGGTCTATTCTC-3', M-F: 5'-GCTTGGTGTGGGGTCTATTCTT-3', R: 5'-

TCCACTCACCTTCCCTCTTCTC-3'; rs6734238: W-F: 5'-TGACAGCGAGGGTCCGAAT-3, M-F: 5'CGACAGATAGGGTCAGAACTTGG-3', R: 5'-GGCAGAATCCCGCCTTACTAC-3'; rs3917368: W-F: 5'CCCAAGCCGATAGGATAAGCC-3', M-F: 5'-GCCCATGCCGATAGGATAAGCT-3', R: 5'-

TTCTGCGATGCGTAGTCTGTAGG-3'.

\section{Simoa assay}

Plasma samples were analyzed using the Simoa HD-1 Analyzer according to the manufacturer's instruction. The sample tube was first positioned and inserted into a channel in a sample holder. The integrated barcode reader read the sample ID barcode as it was inserted into the sample holder. Each sample required two disposable tips, a reaction cuvette and disposable Simoa discs of 24 arrays. When the processing of each sample was complete, the results were computed from the array image file by a 
software algorithm that includes quality control (QC) checks on quality of the data. The measurement results were automatically calculated and displayed in real time after each sample was processed.

Calculations of odds ratio (OR) values and Pearson correlation coefficient

The potential correlation between genotype and disease was analyzed by OR value calculation. OR and $95 \%$ confidence interval $(\mathrm{Cl})$ of each genetic model were calculated by random effect model analysis.

Pearson correlation coefficient, also known as Pearson product-moment correlation coefficient, is a linear correlation coefficient. The correlation coefficient is generally expressed as $\mathrm{R}$, which describes the degree of linear correlation between two variables. If $R>0$, the two variables are positively correlated. If $r<0$, the two variables are negatively correlated. A larger absolute value of $\mathrm{R}$ indicates a stronger correlation.

\section{Statistical analysis}

Statistical analysis was performed using Statistical Product and Service Solutions (SPSS) (IBM, Armonk, NY). Unpaired Student's T-test was used for assessing the significance of differences between two groups. Graphic processing was performed using GraphPad Prism (GraphPad; La Jolla, CA). All data was presented as mean $\pm \mathrm{SD}, P<0.05$ was regarded as being significant.

\section{Results}

\section{Blood sample collection}

Posterior circulation ischemic stroke (PCl) and cerebral infarction $(\mathrm{Cl})$ are common cerebrovascularrelated disorders. To determine biomarkers for $\mathrm{PCl}$ and $\mathrm{Cl}$, we collected whole blood and plasma samples from healthy control and patient subjects. Blood samples were collected from $23 \mathrm{PCl}$ patients, including 11 males and 12 females, aged between 47 and 88 years old, with an average age of 66 . In addition, blood samples were collected from $18 \mathrm{Cl}$ patients, 13 males and 5 females, aged between 15 and 82 years old, with an average age of 59. Blood samples from 39 healthy controls, including 24 females and 15 males, aged between 16 and 72 years old, with an average age of 43 , were served as controls (Table 1). Collected whole blood and plasma samples were stored at $-80^{\circ} \mathrm{C}$ for further analyses.

\section{Difference of SNP mutations among healthy controls, $\mathrm{PCl}$ and Cl subjects}

To explore the potential association of SNP mutations with the risk for $\mathrm{PCl}$ and $\mathrm{Cl}$, genotypes of the 5 SNPs were analyzed by AS-PCR in whole blood samples of all subjects (Table 2). We first analyzed the genomic locations of these SNPs (Figure 1). We found that rs11265259 and rs3093077, rs6734238, and rs4129267 are located in the promoter regions of CRP, IL-1F10 and IL-6R genes, respectively, and rs3917368 is located in the coding region of $I L-1 B$ gene (Figure 1). According to the wild type and mutation sequences of these SNPs, we designed specific amplification primers and performed AS-PCR. 
We did not detect any mutations for CRP rs11265259 and IL-1F10 rs6734238 in all control and patient samples in this study (Table 2). Interestingly, we detected mutations in the other 3 SNPs among both healthy control and patient samples. We calculated the odds ratio (OR) values for each genotype using SPSS software, and compared the risk estimate data to evaluate the risk genotypes for $\mathrm{PCl}$ and $\mathrm{Cl}$ (Figure 2, Table 3). Our calculations showed as the following: $C R P$ rs3093077 (CC+AC vs. $A A: O_{C I}$ s. $H C=1.59$, $\mathrm{OR}_{\mathrm{PCl} \text { vs. } \mathrm{HC}}=0.44, \mathrm{OR}_{\mathrm{Cl}+\mathrm{PCl} \text { vs. } \mathrm{HC}}=0.89 ; \mathrm{AC}$ vs. $\mathrm{AA}: \mathrm{OR}_{\mathrm{Cl} \text { vs. } \mathrm{HC}}=1.83, \mathrm{OR}_{\mathrm{PCl} \text { vs. } \mathrm{HC}}=0.51, \mathrm{OR}_{\mathrm{Cl}+\mathrm{PCl} \text { vs. } \mathrm{HC}}=$ 1.02); $I L-1 B$ rs3917368 (CT+TT vs. $C C: \mathrm{OR}_{\mathrm{Cl} \text { vs. } \mathrm{HC}}=2.25, \mathrm{OR}_{\mathrm{PCl} \text { vs. } \mathrm{HC}}=2.19, \mathrm{OR}_{\mathrm{Cl}+\mathrm{PCl} \text { vs. } \mathrm{HC}}=2.22 ; \mathrm{CT}$ vs. $C C: \mathrm{OR}_{\mathrm{Cl} \text { vs. } \mathrm{HC}}=1.96, \mathrm{OR}_{\mathrm{PCl} \text { vs. } \mathrm{HC}}=1.47, \mathrm{OR}_{\mathrm{Cl}+\mathrm{PCl} \text { vs. } \mathrm{HC}}=1.74 ; \mathrm{TT}^{\mathrm{vs} .} \mathrm{CC}: \mathrm{OR}_{\mathrm{Cl} \text { vs. } \mathrm{HC}}=9.00, \mathrm{OR}_{\mathrm{PCl} \text { vs. } \mathrm{HC}}=$ $\left.18.75, \mathrm{OR}_{\mathrm{Cl}+\mathrm{PCl} \text { vs. } \mathrm{HC}}=13.33\right) ; / L-6 R \mathrm{rs} 4129267\left(\mathrm{CT}+\mathrm{TT}\right.$ vs. $\mathrm{CC}: \mathrm{OR}_{\mathrm{Cl} \text { vs. } \mathrm{HC}}=1.59, \mathrm{OR}_{\mathrm{PCl} \text { vs. } \mathrm{HC}}=1.96$, $\mathrm{OR}_{\mathrm{Cl}+\mathrm{PCl} \text { vs. } \mathrm{HC}}=1.73 ; \mathrm{CT}$ vs. $\mathrm{CC}: \mathrm{OR}_{\mathrm{Cl} \text { vs. } \mathrm{HC}}=1.56, \mathrm{OR}_{\mathrm{PCl} \text { vs. } \mathrm{HC}}=2.14, \mathrm{OR}_{\mathrm{Cl}+\mathrm{PCl} \text { vs. } \mathrm{HC}}=1.79 ; \mathrm{TT}$ vs. $\mathrm{CC}: \mathrm{OR}_{\mathrm{Cl}}$ vs. $\left.\mathrm{HC}=1.67, \mathrm{OR}_{\mathrm{PCI} \text { vs. } \mathrm{HC}}=1.5, \mathrm{OR}_{\mathrm{Cl}+\mathrm{PCl} \text { vs. } \mathrm{HC}}=1.6\right)$.

We found that the OR values of $C R P$ rs 3093077 were less than 1, suggesting that the $C$ allele of $C R P$ rs3093077 may be a protective factor in reducing $\mathrm{PCl}$ and $\mathrm{Cl}$ risk. However, the OR values of $I L-1 B$ rs3917368 and $I L-6 R$ rs4129267 in PCl and Cl samples were greater than 1, compared to those in healthy controls, suggesting that these SNP mutations may increase the risk of $\mathrm{PCl}$ and $\mathrm{Cl}$ (Figure 2). Notably, when the homozygous genotype for the TT mutation was present in $I L-1 B$ rs3917368, the OR values for $\mathrm{PCl}$ and $\mathrm{Cl}$ subjects were as high as 18.75 and 9, respectively, compared to those in healthy controls, suggesting a great increase of disease risk (Figure 2, Table 3). Our results suggest that these three SNPs can be used to predict and evaluate the risk of $\mathrm{PCl}$ and $\mathrm{Cl}$.

\section{Significant differences in CRP levels detected by Simoa}

Because Simoa is a fully automated analysis with higher sensitivity and accuracy compared to conventional methods, we next measured CRP levels in healthy controls, $\mathrm{PCl}$ and $\mathrm{Cl}$ subjects. For the healthy controls, the minimal CRP value was $1.3333 \mathrm{pg} / \mathrm{ml}$, the maximal value was $364.2411 \mathrm{pg} / \mathrm{ml}$, and the average was $44.9273 \mathrm{pg} / \mathrm{ml}$, as measured by Simoa (Table 4). On the other hand, the lowest CRP concentration was measured as $2.5520 \mathrm{pg} / \mathrm{ml}$, the highest was $569.6146 \mathrm{pg} / \mathrm{ml}$, and the average was $159.6868 \mathrm{pg} / \mathrm{ml}$ in plasma samples in the $\mathrm{Cl}$ subjects (Table 4). Moreover, the lowest CRP concentration was $11.3224 \mathrm{pg} / \mathrm{ml}$, the highest was $781.1730 \mathrm{pg} / \mathrm{ml}$, and the average was $281.4760 \mathrm{pg} / \mathrm{ml}$, as measured in plasma samples from the PCl subjects (Table 4). Our Simoa analyses indicate a significant increase of $\mathrm{CRP}$ concentrations in plasma samples from $\mathrm{PCl}$ and $\mathrm{Cl}$ patients, compared to those from healthy controls.

\section{Correlation between SNP mutations and CRP levels}

We next examined whether there is a correlation between SNP mutations and CRP levels detected in healthy controls, $\mathrm{PCl}$ and $\mathrm{Cl}$ subjects. We divided CRP concentrations into four ranges: less than 44.9273 $\mathrm{pg} / \mathrm{ml}, 44.9273-159.6868 \mathrm{pg} / \mathrm{ml}, 159.6868-281.476 \mathrm{pg} / \mathrm{ml}$, and greater than $281.476 \mathrm{pg} / \mathrm{ml}$ (Figure 3 , Table 5). We then calculated the percentages of samples, which carry SNP mutations in each of these four ranges of CRP concentrations, among all samples in that specific range. We detected the 
percentages as the following: IL-1B rs3917368: $64.86 \%, 76.47 \%, 100.00 \%$ and $88.89 \%$; IL-6R rs 4129267 : 60.53\% $, 76.47 \%, 50.00 \%$ and $100.00 \%$; and CRP rs $3093077: 54.05 \%, 44.44 \%, 75.00 \%$ and $30.00 \%$, respectively (Figure 4, Table 5).

Moreover, we performed Pearson correlation coefficient analyses based on SNP mutation percentages in each CRP concentration range for each gene. We found that the correlation coefficient $\mathrm{R}$ for the $I L-1 B$ rs3917368 mutation and CRP levels is 0.81 , suggesting a very high correlation between this SNP mutation and CRP levels (Table 5). The correlation coefficient R for the IL-6R rs4129267 mutation and CRP levels was 0.55 , suggesting a moderate correlation between this SNP mutation and CRP levels. The correlation coefficient $\mathrm{R}$ for the CRP rs3093077 mutation and CRP levels was -0.28 , indicating a negative correlation between them (Table 5).

These results suggest that SNP mutations in $I L-1 B$ rs3917368 and $I L-6 R$ rs4129267 are positively correlated with CRP levels.

\section{Discussion}

Posterior circulation ischemia $(\mathrm{PCl})$ and cerebral infarction $(\mathrm{Cl})$ are common cerebrovascular diseases. Accumulating studies have shown that CRP is directly involved in cardiovascular diseases such as inflammation and atherosclerosis. In this study, we have examined SNP mutations that are associated with $\mathrm{PCl}$ and $\mathrm{Cl}$, detected increased $\mathrm{CRP}$ levels in plasmas from $\mathrm{PCl}$ and $\mathrm{Cl}$ patients using a high sensitive method Simoa. Our study confirms CRP as a potential biomarker for cardiovascular disease, further highlights AS-PCR and Simoa as powerful tools in clinical applications.

Precision medicine, applying accurate screening, auxiliary diagnosis and treatment, is becoming a promise direction in medical research and practice. The IL-1 cytokine family consists of 11 members, which are mainly responsible for controlling pro-inflammatory response to tissue damages, and plays a vital role in many autoimmune diseases (Gabay et al. 2010; Palomo et al. 2015). IL-6 is a multi-functional cytokine, and plays an important role in immune regulation, hematopoiesis, inflammation and tumorigenesis (Jones et al. 2018). IL-6 stimulation results in an activation of the JAK/STAT pathway (Figure 5). Both STAT1 and STAT3 are phosphorylated and are capable of forming homologous and heterologous dimers, which lead to their localization and subsequent regulation of transcription of their target genes, and in turn affect CRP levels (Figure 5). Thus, IL-6, IL-1, and CRP are recognized as ideal targets for diagnosis of disorders related to inflammation. Detecting mutations in SNPs and exploring their associations with disease risk are crucial in early diagnostics of various diseases. In this study, we have assessed SNP mutations and identified potential risks in genes involved in inflammation, which are associated with $\mathrm{PCl}$ and $\mathrm{Cl}$.

Identifying and applying biomarkers associated with diseases are critical for early disease diagnosis and prognosis(Rifai et al. 2006). Proteins and nucleic acids are currently the most broadly used biomarkers in basic research and clinical application. The AS-PCR can conveniently and quickly detect mutations at specific sites of genes. The analysis and interpretation of genotypes by $\triangle \mathrm{Ct}$ are accurate and reliable, 
and the overall cost is far lower than that of high-throughput sequencing (Lang et al. 2011). Therefore, AS-PCR can be used as a powerful genotyping identification tool widely used in risk assessment of specific diseases.

Moreover, because the protein content is much higher than the nucleic acid content, it is becoming a reliable clinical diagnosis target (Simon 2011). Enzyme linked immunosorbent assay (ELISA) uses immune reaction to provide qualitative and quantitative measurement of a target protein, and has been a well-accepted method and a powerful tool in research labs and clinic (Engvall et al. 1971). However, the requirement of a relatively higher protein level has hindered its usage to detect subtle differences among samples and a low level of proteins. The recently developed Simoa technology has overcome the drawbacks of ELISA. Simoa combines automated ELISA with single molecule array termination to enable single molecule sensitivity and multiplex analysis (Chang et al. 2012; Yeung et al. 2016). Simoa has been used to quantify levels of biomarkers associated with diseases such as neurological disorders (Hansson et al. 2017). For example, levels of amyloid- $\beta$ (Aß42) peptide, tau, phosphorylated neurofilament (pNfH), and neurofilament light chain ( $\mathrm{NfL}$ ) have been measured using the Simoa technology (Bjerke et al. 2016; Zetterberg et al. 2011; Mattsson et al. 2016; Rojas et al. 2018; Kasai et al. 2017; Wilke et al. 2019; Kuhle et al. 2019).

As a newer platform, the Simoa technology has demonstrated a great potential to sensitively quantify proteins with a hint amount. However, the current expensive reagents and equipment have limited the broad use of the Simoa technology in research, let along in clinical application. Nevertheless, the fast improvement of the Simoa technology should expand its ground. Along with the ELISA method, Simoa will become a useful tool for clinical diagnosis.

\section{Conclusion}

In summary, SNP screening plays an important role in early detection of the risk assessment of $\mathrm{PCl}$ and Cl. Three SNPs, including rs3093077, rs3917368 and rs4129267, can be used for early screening for disease risk in $\mathrm{PCl}$ and $\mathrm{Cl}$, in particular rs3917368 with a high risk index. In addition, $\mathrm{CRP}$ is one of the potential biomarkers for clinical diagnosis of $\mathrm{PCl}$ and $\mathrm{Cl}$. Our results indicate the high sensitivity of the Simoa technology in detecting plasma CRP levels. Monitoring the level of CRP is helpful to prevent and control the progression of $\mathrm{PCl}$ and $\mathrm{Cl}$.

\section{Abbreviations}

$\mathrm{PCl}$ : Posterior circulation ischemia

$\mathrm{Cl}$ : cerebral infarction

SNP : single nucleotide polymorphism

CRP : C-reactive protein 
AS-PCR : Allele-Specific Polymerase Chain Reaction

Simoa : Single molecule array

IL : InterLeukin

OR : Odds Ratio

SPSS : Statistical Product and Service Solutions

\section{Declarations}

\section{Ethics approval and consent to participate -}

This study was approved by the Institution Ethic Issue Committee of the First Hospital of Quanzhou, Quanzhou, Fujian China (2019-107). Written informed consent was obtained from participants in the study.

\section{Consent for publication -}

Not applicable.

\section{Availability of supporting data -}

The data sets in this study are available from the corresponding author upon request.

\section{Competing interests -}

The authors declare no conflict of interest.

\section{Funding and Acknowledgements-}

This work was supported by the Innovation Awards of Quanzhou Talents (2018C057R), which supported sample collections; and National Natural Science Foundation of China (31771141), which supported experiments and data analyses.

\section{Authors' contributions -}

Conceived and designed the experiments: T.S.; Sampling and result analysis: W.H.C., T.L., L.X., W.J.C., Z.Z., R.L.C. and T.S. Wrote the paper: R.L.C., L.X. and T.S. All authors have read and approved of the final version of the manuscript.

\section{References}


Chen R, Su R, Deng M, Liu J, Hu Q, Song Z. 2018. A Posterior Circulation Ischemia Risk Score System to Assist the Diagnosis of Dizziness. Journal of Stroke and Cerebrovascular Diseases 27(2):506-12.

Murai M, Hazui H, Sugie A, Hoshiga M, Negoro N, Muraoka H, et al. 2008. Asymptomatic Acute Ischemic Stroke After Primary Percutaneous Coronary Intervention in Patients With Acute Coronary Syndrome Might be Caused Mainly by Manipulating Cathetersor Devices in the Ascending Aorta, Regardless of the Approach to the Coronary Artery. Circulation Journal 72(1):51-5.

Pepys MB, Hirschfield GM. 2003. C-reactive protein: a critical update. The Journal of Clinical Investigation 111(12):1805-12.

Qi L. 2009. Mendelian randomization in nutritional epidemiology. Nutr Rev 67(8):439-450.

Raffield LM, lyengar AK, Wang B, et al. 2020. Allelic Heterogeneity at the CRP Locus Identified by WholeGenome Sequencing in Multi-ancestry Cohorts. Am J Hum Genet 106(1):112-120.

Sabater-Lleal M, Huang J, Chasman D, et al. 2013. Multiethnic meta-analysis of genome-wide association studies in $>100000$ subjects identifies 23 fibrinogen-associated Loci but no strong evidence of a causal association between circulating fibrinogen and cardiovascular disease. Circulation 128(12):1310-1324.

Fujii R, Hishida A, Wu MC, et al. 2018. Genome-wide association study for

pollinosis identified two novel loci in interleukin (IL)-1B in a Japanese population. Nagoya J Med Sci 80(1):109-120.

Gabay C., Kushner I. 1999. Acute-phase proteins and other systemic responses to inflammation. New England Journal of Medicine 340(6):448-54.

Darawi, M.N., Ai-Vyrn, C., Ramasamy, K. et al. 2013. Allele-specific polymerase chain reaction for the detection of Alzheimer's disease-related single nucleotide polymorphisms. BMC Med Genet 14, 27

Kwok PY, Chen X. 2003. Detection of single nucleotide polymorphisms. Curr Issues Mol Biol 5: 43-60.

Chen Q, Lu P, Jones AV, Cross NC, Silver RT, Wang L. 2007. Amplification refractory mutation system, a highly sensitive and simple polymerase chain reaction assay, for the detection of JAK2 V617F mutation in chronic myeloproliferative disorders. J Mol Diagn 9: 272-276.

Mirasena S, Shimbhu D, Sanguansermsri M, Sanguansermsri T. 2008. Detection of beta-thalassemia mutations using a multiplex amplification refractory mutation system assay. Hemoglobin 32: 403-409.

Gabay C, Lamacchia C, Palmer G. 2010. IL-1 pathways in inflammation and human diseases. Nat Rev Rheumatol 6(4):232-241.

Palomo J, Dietrich D, Martin P, Palmer G, Gabay C. 2015. The interleukin (IL)-1 cytokine family-Balance between agonists and antagonists in inflammatory diseases. Cytokine 76(1):25-37. 
Jones BE, Maerz MD, Buckner JH. 2018. IL-6: a cytokine at the crossroads of

autoimmunity. Curr Opin Immunol 55:9-14.

Rifai N, Gillette MACarr SA. 2006. Protein biomarker discovery and validation: the long and uncertain path to clinical utility. Nature Biotechnology 24(8):971-83.

Lang A H, Drexel H, Geller-Rhomberg S, et al. 2011. Optimized allele-specific real-time PCR assays for the detection of common mutations in KRAS and BRAF[J]. The Journal of Molecular Diagnostics 13(1): 2328.

Simon R. 2011. Genomic biomarkersin predictive medicine: an interim analysis. Embo Molecular Medicine 3(8):429-35.

Engvall E, Perlmann P. 1971. Enzyme-linked immunosorbent assay (ELISA). Quantitative assay of immunoglobulin G. Immunochemistry 8(9):871-4.

Chang L, Rissin DM, Fournier DR, Piech T, Patel PP, Wilson DH, et al. 2012. Single molecule enzyme-linked immunosorbent assays: Theoretical considerations. Journal of Immunological Methods 378(1):102-15.

Yeung D, Ciotti S, Purushothama S, Gharakhani E, KuestersG, Schlain B, et al. 2016. Evaluation of highly sensitive immunoassay technologies for quantitative measurements of sub- $\mathrm{pg} / \mathrm{mL}$ levels of cytokines in human serum. Journal of Immunological Methods 437:53-63.

Hansson O, Janelidze S, Hall S, Magdalinou N, Lees AJ, Andreasson U, et al. 2017. Blood-based NfL. Neurology 88(10):930.

Bjerke M, Andreasson U, Kuhlmann J, Portelius E, Pannee J, Lewczuk P, et al. 2016. Assessing the commutability of reference material formats for the harmonization of amyloid- $\beta$ measurements. Clinical Chemistry and Laboratory Medicine (CCLM) p. 1177.

Zetterberg H, Mörtberg E, Song L, Chang L, Provuncher GK, Patel PP, et al. 2011. Hypoxia Due to Cardiac Arrest Induces a Time-Dependent Increase in Serum Amyloid $\beta$ Levels in Humans. PLOS ONE 6(12):e28263.

Mattsson N, Zetterberg H, Janelidze S, Insel PS, Andreasson U, Stomrud E, et al. 2018. Plasma tau in Alzheimer disease. Neurology 87(17):1827.

Rojas JC, Bang J, Lobach IV, Tsai RM, Rabinovici GD, Miller BL, et al. 2018. CSF neurofilament light chain and phosphorylated tau 181 predict disease progression in PSP. Neurology 90(4):e273.

Kasai T, Tatebe H, Kondo M, Ishii R, Ohmichi T, Yeung WTE, et al. 2017. Increased levels of plasma total tau in adult Down syndrome. PLOS ONE. 12(11):e0188802. 
Wilke C, Pujol-Calderón F, Barro C, Stransky E, Blennow K, Michalak Z, et al. 2019. Correlations between serum and CSF pNfH levels in ALS, FTD and controls: a comparison of three analytical approaches. Clinical Chemistry and Laboratory Medicine (CCLM) p. 1556.

Kuhle J, Kropshofer H, Haering DA, Kundu U, Meinert R, Barro C, et al. 2019. Blood neurofilament light chain as a biomarker of MS disease activity and treatment response. Neurology 92(10):e1007.

\section{Tables}

Table 1. Whole blood and plasma sample collection.

\begin{tabular}{|llll|}
\hline & $\mathrm{HC}$ & $\mathrm{PCl}$ & $\mathrm{Cl}$ \\
\hline Number & 39 & 23 & 18 \\
\hline Sex (F/M) & $24 / 15$ & $12 / 11$ & $5 / 13$ \\
\hline Average age (range) & $43(16-72)$ & $66(47-88)$ & $59(15-82)$ \\
\hline
\end{tabular}

Whole blood and plasma samples consisted of 39 healthy controls $(\mathrm{HC}), 23$ posterior circulation ischemia (PCl) and 18 cerebral infarction ( $\mathrm{Cl})$ subjects, including males and females of different ages.

Table 2. Detection of polymorphisms in 5 candidate SNPs using AS-PCR. 


\begin{tabular}{|c|c|c|c|c|}
\hline Genes and SNPs & Subjects & $\begin{array}{l}\text { Wild type } \\
\text { /cases }\end{array}$ & $\begin{array}{l}\text { Mutant } \\
\text { heterozygote/ } \\
\text { cases }\end{array}$ & $\begin{array}{l}\text { Mutant } \\
\text { homozygote/ } \\
\text { cases }\end{array}$ \\
\hline \multirow{3}{*}{$\begin{array}{l}\text { CRP } \\
\text { rs11265259 }\end{array}$} & $\mathrm{HC}$ & 39 & 0 & 0 \\
\hline & $\mathrm{Cl}$ & 23 & 0 & 0 \\
\hline & $\mathrm{PCl}$ & 18 & 0 & 0 \\
\hline \multirow{3}{*}{$\begin{array}{l}C R P \\
(\mathrm{~A}>\mathrm{C})\end{array}$} & $\mathrm{HC}$ & 16 & 20 & 3 \\
\hline & $\mathrm{Cl}$ & 7 & 16 & 0 \\
\hline & $\mathrm{PCl}$ & 11 & 7 & 0 \\
\hline \multirow{3}{*}{$\begin{array}{l}\text { IL-1F10 } \\
\text { rs6734238 }\end{array}$} & $\mathrm{HC}$ & 39 & 0 & 0 \\
\hline & $\mathrm{Cl}$ & 23 & 0 & 0 \\
\hline & $\mathrm{PCl}$ & 18 & 0 & 0 \\
\hline \multirow{3}{*}{$\begin{array}{l}\text { IL-1B } \\
\text { rs3917368 } \varangle C>T \otimes\end{array}$} & $\mathrm{HC}$ & 15 & 23 & 1 \\
\hline & $\mathrm{Cl}$ & 5 & 15 & 3 \\
\hline & $\mathrm{PCl}$ & 4 & 9 & 5 \\
\hline \multirow{3}{*}{$\begin{array}{l}\text { IL-6R } \\
\text { rs4129267凶C > T区 }\end{array}$} & $\mathrm{HC}$ & 14 & 18 & 7 \\
\hline & $\mathrm{Cl}$ & 6 & 12 & 5 \\
\hline & $\mathrm{PCl}$ & 4 & 11 & 3 \\
\hline
\end{tabular}

The 5 SNPs for CRP, IL-1F10, IL-1B and IL-6R genes, and the numbers of cases of different genotypes in the healthy controls $(\mathrm{HC})$, posterior circulation ischemia $(\mathrm{PCl})$ and cerebral infarction $(\mathrm{Cl})$ subjects. The genotypes include wild type, mutant heterozygote and mutant homozygote.

Table 3. Odds ratio (OR) values of different genotypes in CRP (rs3093077), IL-1B (rs 3917368) and IL-6R (rs4129267). 


\begin{tabular}{|lllll|}
\hline Genes and SNPs & Genotypes & $\mathrm{PCl}$ vs HC & Cl vs $\mathrm{HC}$ & $\mathrm{PCl}+\mathrm{Cl}$ vs HC \\
\hline CRP & CC+AC vs. AA & 0.44 & 1.59 & 0.89 \\
rs3093077 & AC vs. AA & 0.51 & 1.83 & 1.02 \\
\hline IL-1B & CT+TT vs. CC & 2.19 & 2.25 & 2.22 \\
rs3917368 & CT vs. CC & 1.47 & 1.96 & 1.74 \\
\cline { 2 - 5 } & TT vs. CC & 18.75 & 9.00 & 13.33 \\
IL-6R rs4129267 & CT+TT vs. CC & 1.96 & 1.59 & 1.74 \\
\cline { 2 - 5 } & CT vs. CC & 2.14 & 1.56 & 1.79 \\
\cline { 2 - 5 } & TT vs. CC & 1.50 & 1.67 & 1.60 \\
\cline { 2 - 5 } & & &
\end{tabular}

The OR values of different genotypes were calculated in samples of the healthy controls (HC), posterior circulation ischemia $(\mathrm{PCl})$ and cerebral infarction $(\mathrm{Cl})$ subjects.

Table 4. Measurements of CRP concentrations detected by the Simoa method.

\begin{tabular}{|lllll|}
\hline \multirow{3}{*}{ Simoa } & & $\mathrm{HC}$ & $\mathrm{PCl}$ & $\mathrm{Cl}$ \\
\cline { 2 - 6 } & Mean $(\mathrm{pg} / \mathrm{ml})$ & 44.9273 & $281.476^{\star \star \star}$ & $159.6868^{\star \star \star}$ \\
\cline { 2 - 5 } & Maximum & 364.2411 & 781.173 & 496.4574 \\
\cline { 2 - 5 } & Minimum & 1.3333 & 11.3224 & 2.552 \\
\hline
\end{tabular}

Plasma samples consisted of 39 healthy controls $(\mathrm{HC}), 23$ posterior circulation ischemia $(\mathrm{PCl})$ and 18 cerebral infarction $(\mathrm{Cl})$ subjects, including males and females of different ages. The Simoa was measured as $\mathrm{pg} / \mathrm{ml}$. Unpaired Student's t-test was used for assessing the significance of differences between two groups. $* \star *: P<0.001$.

Table 5. The percentages of samples, which carry SNP mutations in each of four ranges of CRP concentrations, among all samples in that specific range. 


\begin{tabular}{|c|c|c|c|}
\hline SNPs & $\begin{array}{l}\text { CRP } \\
\text { concentration } \\
\square p g / m l \square\end{array}$ & $\begin{array}{l}\text { Mutation } \\
\text { percentages } \\
(\%)\end{array}$ & $\begin{array}{l}\text { Pearson correlation coefficient } \\
\text { (R) }\end{array}$ \\
\hline \multirow{4}{*}{$\begin{array}{l}\text { IL-1B } \\
\text { rs3917368هC>T区 }\end{array}$} & $<44.9273$ & 64.86 & \multirow[t]{4}{*}{0.81} \\
\hline & $\begin{array}{l}44.9273- \\
159.6868\end{array}$ & 76.47 & \\
\hline & $\begin{array}{l}159.6868- \\
281.476\end{array}$ & 100.00 & \\
\hline & $>281.476$ & 88.89 & \\
\hline \multirow{4}{*}{$\begin{array}{l}I L-6 R \\
\text { rs4129267هC>T区 }\end{array}$} & $<44.9273$ & 60.53 & \multirow[t]{4}{*}{0.55} \\
\hline & $\begin{array}{l}44.9273- \\
159.6868\end{array}$ & 76.47 & \\
\hline & $\begin{array}{l}159.6868- \\
281.476\end{array}$ & 50.00 & \\
\hline & $>281.476$ & 100.00 & \\
\hline \multirow{4}{*}{$\begin{array}{l}C R P \quad \text { rs3093077(A> } \\
\text { C) }\end{array}$} & $<44.9273$ & 54.05 & \multirow[t]{4}{*}{-0.28} \\
\hline & $\begin{array}{l}44.9273- \\
159.6868\end{array}$ & 44.44 & \\
\hline & $\begin{array}{l}159.6868- \\
281.476\end{array}$ & 75.00 & \\
\hline & $>281.476$ & 30.00 & \\
\hline
\end{tabular}

Figures 


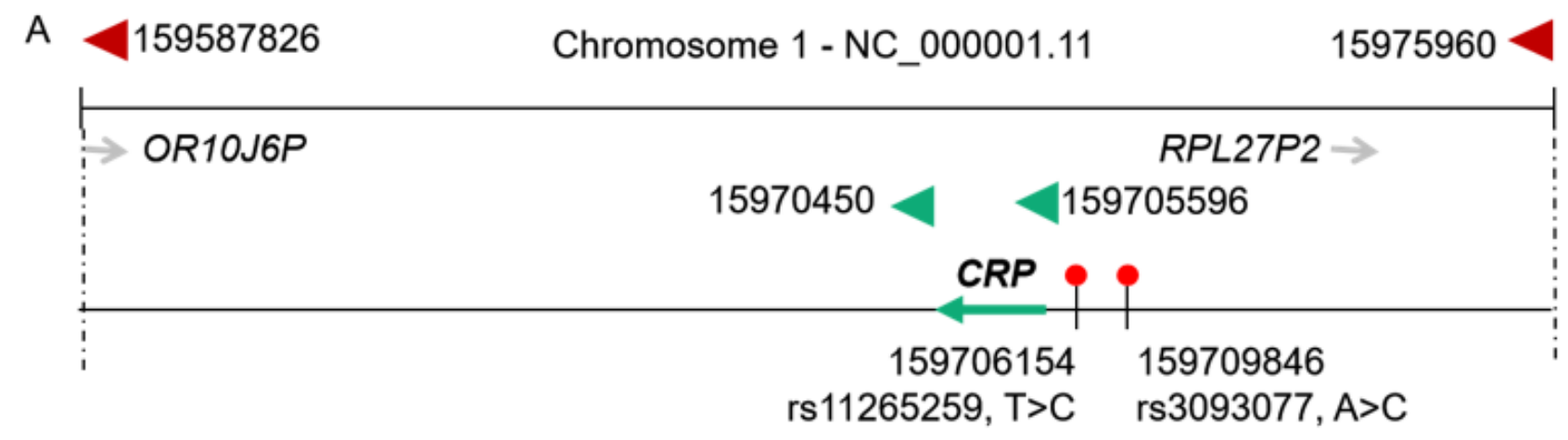

B

113022089

Chromosome 2 - NC_000002.12

113088886

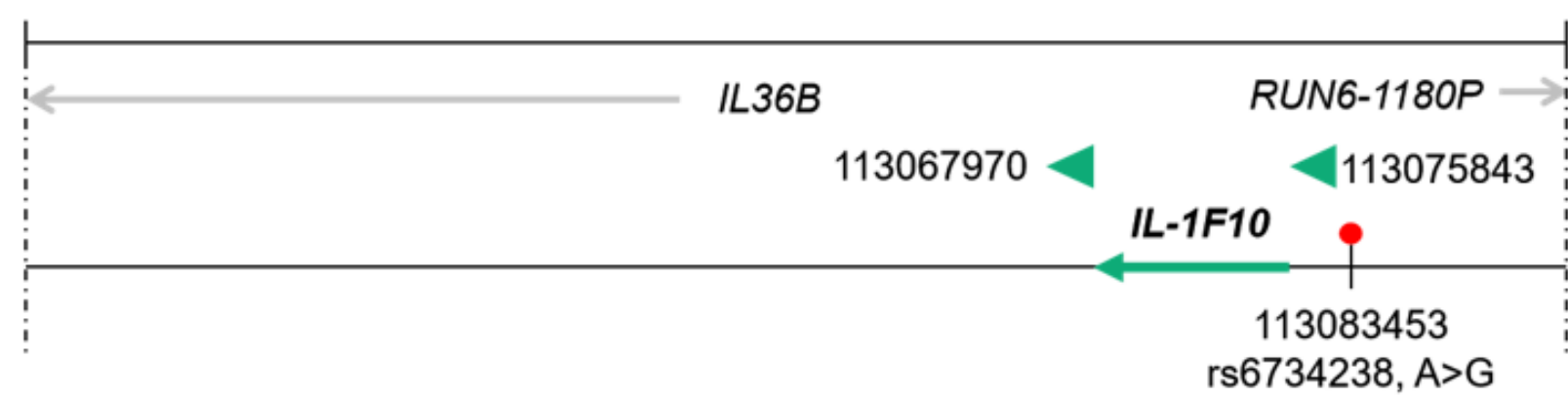

C

Chromosome 2 - NC_000002.12

112898945

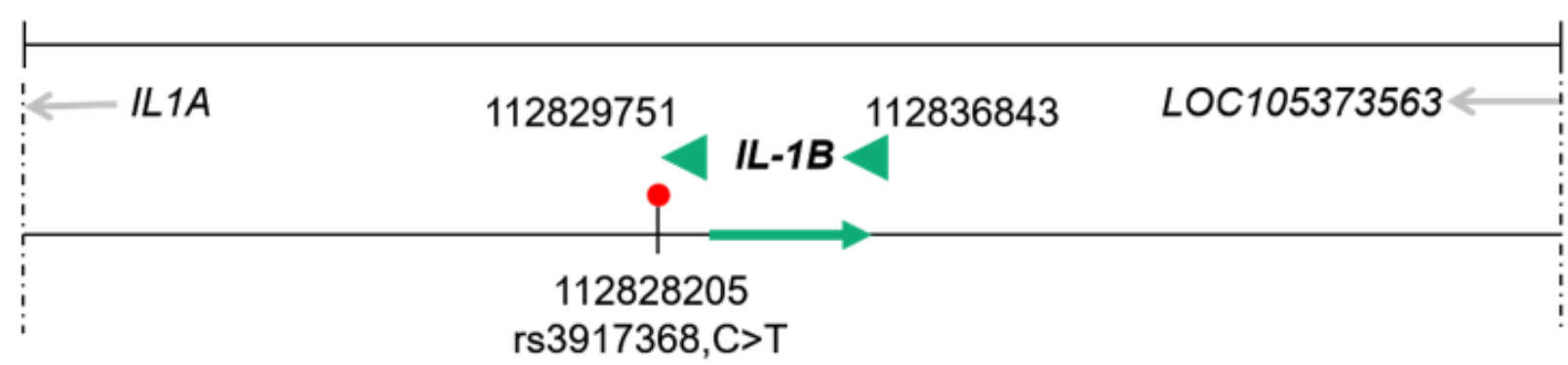

D

154325525

Chromosome 1 - NC_000001.11

154558662

\section{Figure 1}

SNP information of IL-1B, IL-1F10, IL-6R and CRP genes. A. The positions (promoter region) of SNP rs3093077 and rs11265259 of the CRP gene in human chromosome 1. B. The position (promoter region) of SNP rs6734238 of IL-1F10 gene in chromosome 2. C. The position (promoter region) of SNP rs3917368 of IL-1B gene in chromosome 2. D. The position (coding region) of SNP rs4129267 of IL-6R gene in chromosome 1. The arrow indicates the direction of transcription of the gene. 


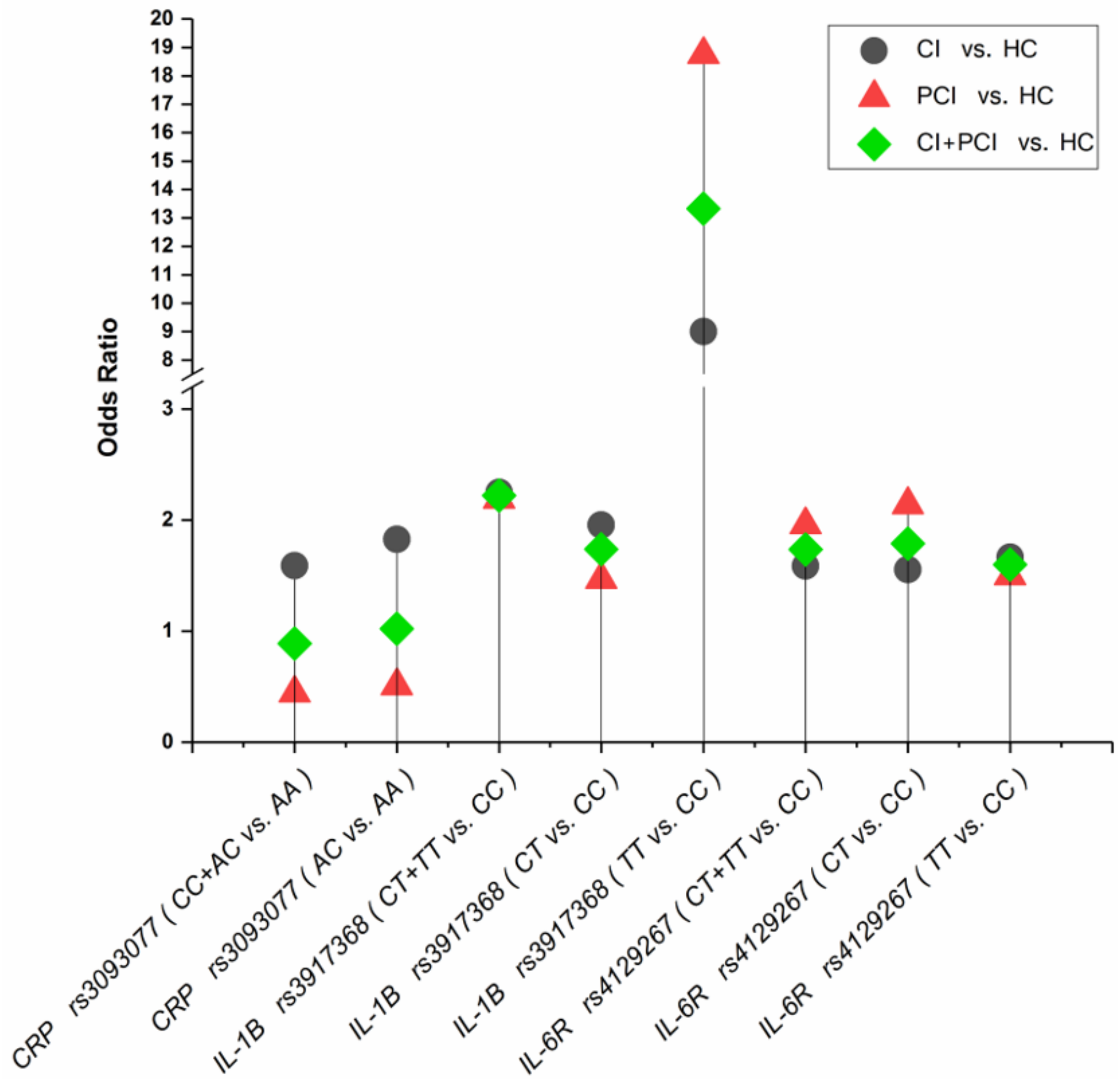

Figure 2

Odds ratio (OR) values of different genotypes of IL-1B rs 3917368, IL-6R rs4129267 and CRP rs3093077 in $\mathrm{PCl}$ and $\mathrm{Cl}$ samples. The $\mathrm{OR}$ values of different genotypes were calculated and compared in samples of the healthy controls $(\mathrm{HC})$, posterior circulation ischemia $(\mathrm{PCl})$ and cerebral infarction $(\mathrm{Cl})$ subjects. 


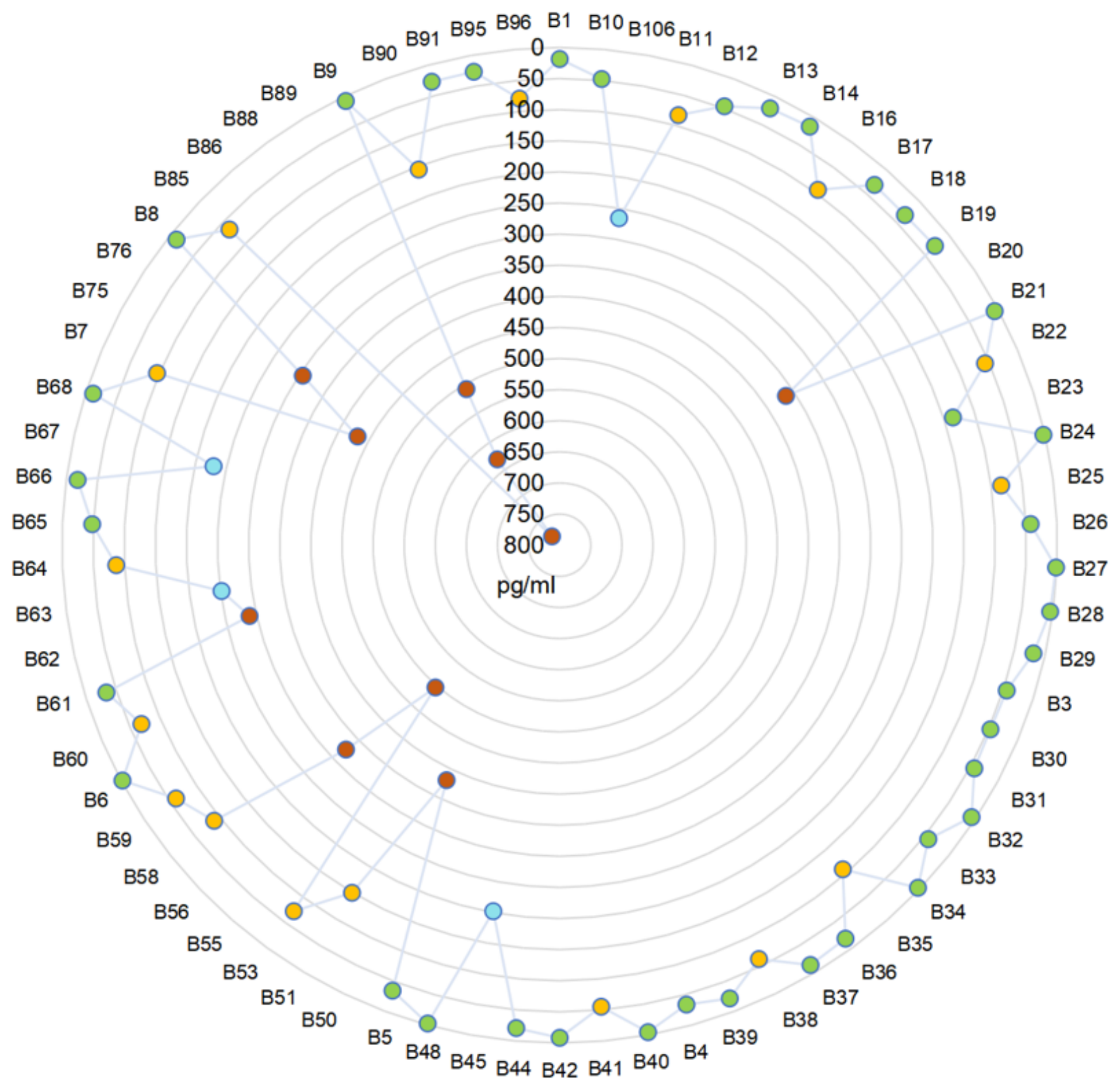

Figure 3

Concentrations of CRP in plasma samples. The green dots represent the sample concentration $<44.9273$ $\mathrm{pg} / \mathrm{ml}$, the orange dots represent the sample concentration 44.9273-159.6868 pg/ml, the light blue dots represent the sample concentration $159.6868-281.476 \mathrm{pg} / \mathrm{ml}$, and the dark brown dots represent the sample concentration $>281.476 \mathrm{pg} / \mathrm{ml}$. Codes of each sample were listed outside the circle. 


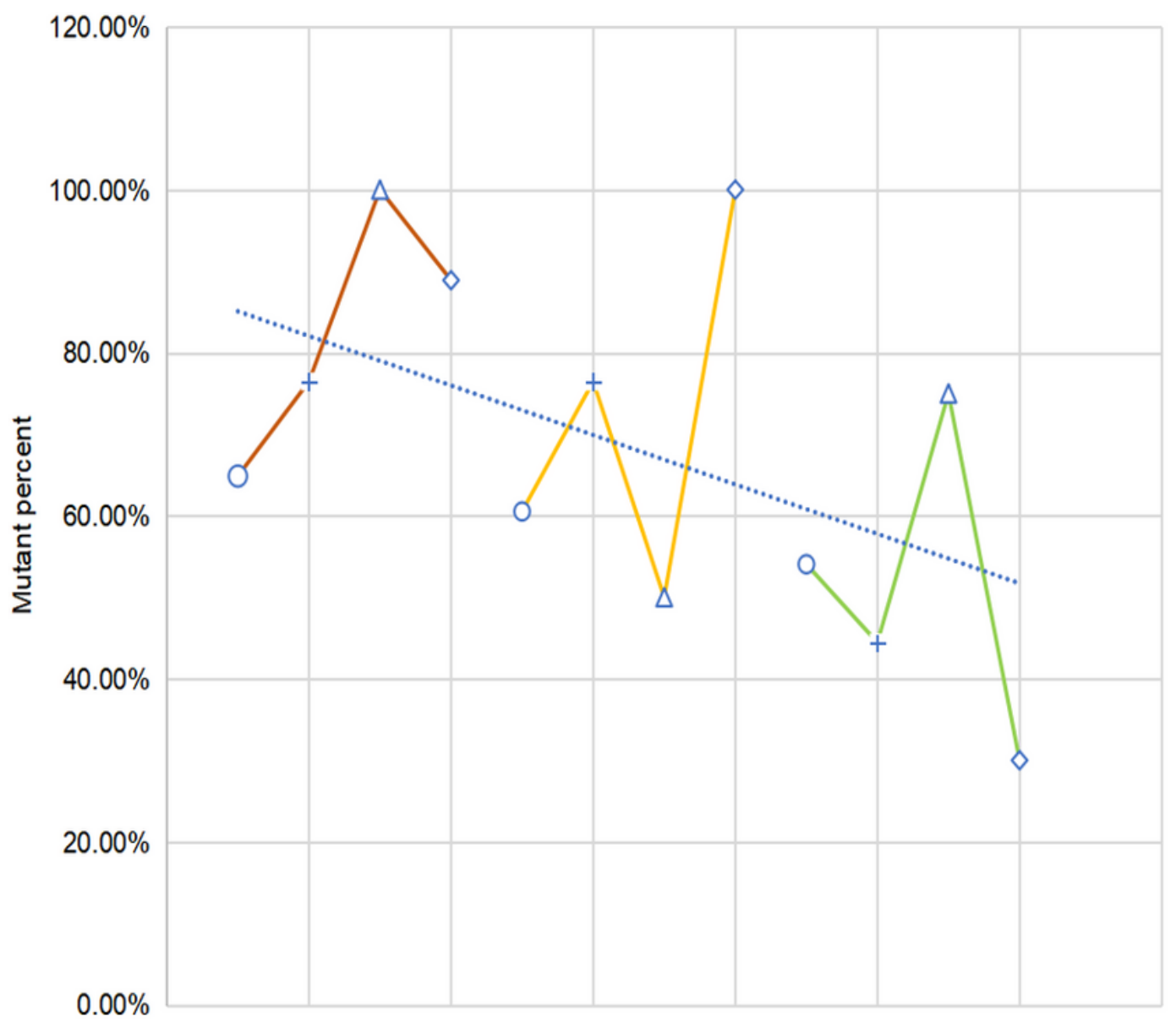

\section{Figure 4}

Percentages of samples, which carry SNP mutations in each of four ranges of CRP concentrations, among all samples in that specific range. Dark brown lines represent IL-1B rs3917368 (C>T), orange lines represent IL-6R rs4129267 (C>T), and green lines represent CRP rs3093077 (A > C). Circles(O) represent the sample concentration $<44.9273 \mathrm{pg} / \mathrm{ml}$, plus signs $(+)$ represent the sample concentration 44.9273$159.6868 \mathrm{pg} / \mathrm{ml}$, triangles $(\triangleleft)$ represent the sample concentration $159.6868-281.476 \mathrm{pg} / \mathrm{ml}$, and diamonds $(\diamond)$ represent the sample concentration $>281.476 \mathrm{pg} / \mathrm{ml}$. 


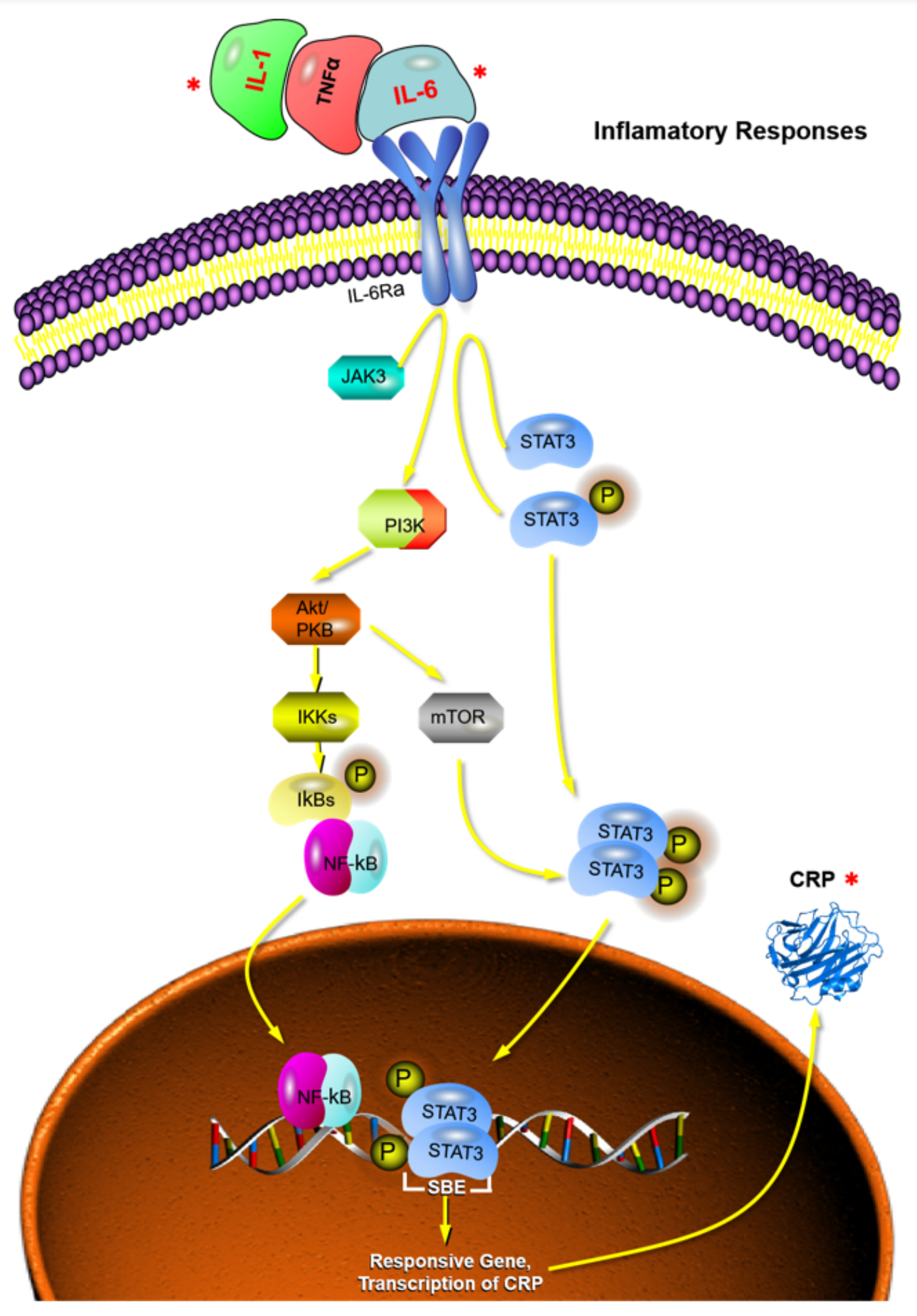

\section{Figure 5}

Signaling pathway of IL-1, IL-6R and CRP. The activity and expression levels of IL- 1 and IL- 6 directly affect the activation state of the JAK/STAT pathway, regulate transcription of target genes, and in turn determine CRP levels. The yellow arrow indicates the transduction direction of the signaling pathway. 